\title{
Evaluation of $C$. albicans Adhesion and Growth on Restorative Dental Materials Enriched or not with Fluoride
}

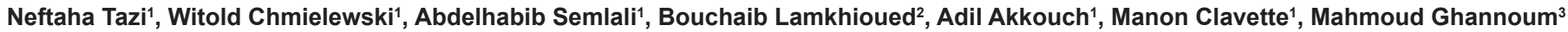 \\ and Mahmoud Rouabhia ${ }^{1 *}$ \\ ${ }^{1}$ Groupe de Recherche en Écologie Buccale, Faculté de Médecine Dentaire, Université Laval, Québec City, Québec, Canada \\ ${ }^{2}$ Laboratoire d'Immunologie et de Microbiologie EA3796, IFR53, UFR de Pharmacie 1 avenue du Maréchal Juin 51100 Reims, France \\ ${ }^{3}$ Center for Medical Mycology, Department of Dermatology, School of Medicine, Case Western Reserve University and University Hospitals Case Medical Center, Cleveland, \\ Ohio, USA
}

\begin{abstract}
Candida albicans (C. albicans) is the most prevalent fungus in the human oral cavity and has been known as the primary cause of denture-related stomatitis. Candida cells have a high adhering potential to dental material in almost the same manner as to oral tissues, and they are known to form biofilm that leads to $C$. albicans resistance against antifungal drugs. The aim of this study was to investigate $C$. albicans adhesion and growth on different restorative dental materials and studied the effect of fluoride on $C$. albicans growth and morphological transition. To this end, C. albicans (Sc 5314) was cultured on acrylic resins, composite resin, and glass-ionomer materials. Growth was analyzed at various times using scanning electron microscopy analyses and cell proliferation assay. The effect of different concentrations (50 and $100 \mathrm{ppm}$ ) of exogenous fluoride on C. albicans growth and yeast-to-hyphae transition was investigated.

Scanning electron microscopy showed that $C$. albicans adhered to all of the tested restorative materials. Adhesion was greater on diamond $\mathrm{D}$ and ivocap than on composite resin and glass ionomer. After 1 to 4 days, C. albicans growth on acrylic resins was two folds that of the composite resin and the glass-ionomer. The latter also displayed the lowest adhesion and growth which may be due to the release of antimicrobial molecules such as fluoride present in this material. This hypothesis is supported by our results showing that exogenous fluoride significantly inhibits $C$. albicans growth and its morphological changes from blastospore to hyphal form. This study clearly demonstrates that restorative materials are conducive to $C$. albicans adhesion and growth. Exogenous fluoride was also shown to down-regulate $C$. albicans growth and morphological changes. Overall data suggest the possible integration of fluoride into dental materials which may control oral microbial pathogenesis.
\end{abstract}

Keywords: Dental materials; C. albicans; Fluoride

\section{Introduction}

Multiple structures such as the mucosa and the teeth contribute to the overall function of the oral cavity. Furthermore, restorative materials are frequently used to replace non-functional elements in the oral cavity $[1,2]$. All available surfaces in the oral cavity are in contact with a plethora of microorganisms that include a large number of bacteria and yeasts. The presence of these microbes on all accessible surfaces of the mouth is both natural and essential for the normal development of the physiology of the oral cavity [3]. The resident oral microflora contributes to the health of the host by preventing exogenous microbial infection, and regulates the inflammatory host response to oral commensal bacteria [3]. Under certain circumstances, however, commensal microorganisms may lead to oral diseases such as caries and candidiasis [4]. Pathogenesis of commensal oral microorganisms is favored by their continuous presence in the oral cavity, profiting by the host immune deregulation. The continuous presence of microorganisms in the oral cavity is promoted by their adhesion to the different surfaces including restorative dental materials. Glass ionomer cements have wide spread clinical indications, being used as temporary and restorative dental materials [5]. The reasons for such a useful clinical versatility are related to the constant fluoride release [6], adhesion to dental tissues and base metals [7], biocompatibility and low coefficient of thermal expansion [8]. The composite resins are also currently used for dental restoration. According to the natural features, the composite resins used for dentin buildup are fabricated and are characterized by lower translucency, whereas the composite resins for enamel are highly translucent [9]. In an attempt to reproduce the enamel properties, high-, medium, and low-value resin composites were introduced, and they are increasingly used for stratified restorations using direct composite resins [10]. Following their introduction in the oral cavity, these restorative dental materials could be additional surfaces for bacterial adhesion and biofilm formation which often lead to local and systemic infections [11].

Biofilm formation is a stepwise process initiated by the adhesion of planktonic bacteria on every surface in the oral cavity, whether these are natural or dental materials $[12,13]$. This process progresses from colonization and co-adhesion via growth and maturation to the detachment and spreading of the microorganisms from the biofilm $[14,15]$. In biofilm formation, early colonization is considered to be the most important step, depending on the nature of the host surface.

*Corresponding author: Mahmoud Rouabhia, Groupe de Recherche en Écologie Buccale, Faculté de Médecine Dentaire, 2420, rue de la Terrasse, Université Laval, Québec (Québec) G1V 0A6, Canada, E-mail: mahmoud.rouabhia@fmd.ulaval.ca

Received January 12, 2012; Accepted February 17, 2012; Published February 24, 2012

Citation: Tazi N, Chmielewski W, Semlali A, Lamkhioued B, Akkouch A, et al (2012) Evaluation of C. albicans Adhesion and Growth on Restorative Dental Materials Enriched or not with Fluoride. J Microbial Biochem Technol 4: 015-021. doi:10.4172/1948-5948.1000066

Copyright: ( 2012 Tazi N, et al. This is an open-access article distributed under the terms of the Creative Commons Attribution License, which permits unrestricted use, distribution, and reproduction in any medium, provided the original author and source are credited 
It is now well documented that a bacterium adheres directly to the saliva coated host surface before exhibiting extensive inter- and intrageneric coaggregations [16]. Thus the physical and chemical properties of the surface materials may affect the feasibility of bacterial infection [17]. To prevent biofilm formation and host infection, surfaces of restorative materials must therefore harbor the appropriate physical and chemical properties.

Correlations between bacterial adhesion and various surface characteristics (chemical composition, surface energy, surface roughness, and the presence of functional groups on the surface) have been studied in an effort to reduce bacterial adhesion through surface modification $[18,19]$. Adequate finishing and polishing of restorative materials, such as composite resins, is a prerequisite for high-quality aesthetics and enhanced longevity of resin-based restorations [20]. Smooth, highly polished restorations are easier to maintain than are restorations with a more roughened surface. They are also less susceptible to plaque accumulation and extrinsic discoloration, and display improved mechanical properties [21-23].

Other initiatives were undertaken to prevent microorganism adhesion and growth and biofilm formation, including the incorporation of antimicrobial molecules [24,25], such as fluoride into restorative materials [26,27]. Fluoride modifies the structure of dental hard tissues by increasing the resistance to acids and imparting antibacterial properties to prevent the growth of harmful bacteria and the formation of biofilm $[28,29]$. Glass-ionomer, a restorative material containing fluoride, was shown to have an inhibitory effect on the growth and adherence of oral bacteria which was attributed to the release of fluoride [30].

Bacteria are not the only microorganisms inhabiting the oral cavity. Yeasts such as C. albicans are frequently encountered in the mouth [31]. C. albicans is the most prevalent yeast isolated from the human body as an opportunist pathogen [32], and has been widely associated with the etiology of denture related stomatitis $[33,34]$. C. albicans can adhere to the denture surface and can forms biofilms [35]. It is well known that biofilm cells typically exhibit increased resistance to antifungal agents and the host immune defence [36,37]. The addition of anti-candidal molecule such as histatin-5 to denture acrylic material showed Candida growth reduction and reduces the formation of bioflims [38]. Our first aim is to determine the adherence and growth of C. albicans on the surfaces of four different restorative materials such as composite resin (Filtek ${ }^{\text {rx }}$ Supreme Plus), acrylic resins (diamond D, Ivocap) and glassionomer (GC Fuji II LC capsule). Our second aim is to investigate the effect of fluoride on C. ablicans growth and yeast-to-hyphae morphological changes.

\section{Experimental Procedures}

\section{Preparation of restorative material disks}

Capsule of glass-ionomer restorative material GC FygilI (GC America Inc., Alsil, IL, USA) was shaken after mixing the powder and liquid components. The capsule was then immediately activated with Vari-mic ${ }^{\mathrm{R} I I}$ Caulk (Dentsply International Inc., Toronto, ON, Canada) and the material was poured into one well of a 96-well plate to produce glass-ionomer disks (6 $\mathrm{mm}$ diameter and $4 \mathrm{~mm}$ thickness). This step was repeated as much as required to obtain the appropriate number of disks. The poured material in each well was light-cured for $30 \mathrm{~s}$ on each side (top and bottom) using a visible light curing device (3M ESPE Dental Products, London, ON, Canada). Following polymerization, the disks were polished as described below. Resin composite disks were prepared using a Filtek TM Supreme Ultra resin composite syringe (3M ESPE). Resin composite in the syringe was poured into the wells of a 96-well plate at a $160 \mathrm{mg} /$ well and prepared as recommended by the manufacturer.

\section{Acrylic resin sample preparation}

Two categories of acrylic resin (Diamond D and Ivocap) restorative materials were used in this study.

\section{Diamond D specimens}

Acrylic resin disks $12 \mathrm{~mm}$ in diameter were customized. To do so, a mixture of regular plaster (Kerr Corporation, Orange, CA, USA) was prepared by mixing $100 \mathrm{~g}$ of stone powder with $45 \mathrm{ml}$ of water and pouring the mixture into a half flask. A $12 \mathrm{~mm}$ diameter cylindrical form was placed into this half flask prior to stone drying. The other half of the flask was prepared by using $100 \mathrm{~g}$ of hydrock rapid stone (Kerr Corporation) mixed with $30 \mathrm{ml}$ of water. This was assembled with the first one and left to dry. Thereafter, the cylindrical form was removed, leaving an empty mould. This dry stone mould was then invested with auto-polymerized acrylic resin (Diamond $\mathrm{D}^{\mathrm{R}}$, Keystone Industries, Cherry Hill, NJ, USA). Diamond D material was prepared by mixing $2 \mathrm{~g}$ of methylpolymethacrylate (Keystone) with $10 \mathrm{ml}$ of a solution containing methyl-methacrylate, ethylene glycol dimethacrylate, with monomethyl ether hydroquinone as an inhibitor. This mixture was placed into the mould and the flask was then pressed with a hydraulic press (Herbst hydrofix, Brenner Goldschlager, West Germany) at $100 \mathrm{kp} / \mathrm{cm}^{2}$ for $15 \mathrm{~min}$. This step was repeated twice to remove excess materials. The resin in the flask was then immersed in a $77^{\circ} \mathrm{C}$ hot water bath for $90 \mathrm{~min}$, and then transferred to a second water bath at $100^{\circ} \mathrm{C}$ for $30 \mathrm{~min}$, after which time the flask with acrylic resin was cooled down at room temperature. The acrylic resin specimen was subsequently polished and $3 \mathrm{~mm}$-thick cylindrical specimens were prepared.

\section{Ivocap specimens}

Acrylic resin disks $12 \mathrm{~mm}$ in diameter were also custom made. To do so, a stone mould was prepared as described in the Diamond D acrylic resin preparation. This dry stone mould was then invested with auto-polymerized acrylic resin. The Ivocap material was prepared by mixing the contents of one capsule containing $20 \mathrm{~g}$ polymer and $30 \mathrm{ml}$ of monomer (Ivoclar Vivadent Inc. Mississauga, ON, Canada). This mixture was then injected into the mould and the flask was pressed with a hydraulic press (Herbst hydrofix; Brenner Goldschlager) at $6 \mathrm{kp} /$ $\mathrm{cm}^{2}$ for $10 \mathrm{~min}$. The flasks were then immersed in a $100^{\circ} \mathrm{C}$ hot water bath for $36 \mathrm{~min}$, after which time the flask containing the acrylic resin was then cooled down at room temperature. The Ivocap acrylic resin specimens were removed from the flask and polished and $3 \mathrm{~mm}$-thick cylindrical specimens were prepared.

\section{Specimen polishing}

Specimens of each restorative material were assigned to a sequential polishing procedure. The procedure consisted of three steps which were based on the sequential application of $\mathrm{SiC}$ papers (Struers Inc. Canada, Mississauga, ON, Canada) having \#800, \#1200 and \#4000 grit. To reduce variability in the specimen preparation, a single operator practiced and confirmed the polishing pressure with a balance in advance and carried out the polishing procedure in sequence as previously reported [39]. After completing each polishing step using a specific grit, the specimens were extensively washed in PBS to remove any debris, after which time they were sterilized $24 \mathrm{~h}$ by incubation in penicillin $(250 \mathrm{mg} / \mathrm{ml})$ and streptomycin $(10 \mathrm{mg} / \mathrm{ml})$ solution, and then washed extensively with sterile PBS to completely move out antibiotics. 


\section{C. albicans growth}

C. albicans (Strain SC5314) was used in this study. Strain SC5314 was chosen because of its widespread and increasing use in molecular analyses, virulence in animal models, and apparent standard diploid electrophoretic karyotype [40]. C. albicans (SC5314) was inoculated into $10 \mathrm{ml}$ of proteinase induction medium (PIM) containing $2 \%$ glucose, $0.1 \% \mathrm{KH} 2 \mathrm{PO} 4,0.05 \% \mathrm{MgSO} 4$, was dissolved in deionised water and adjusted to $\mathrm{pH} 4.0$ (Difco; Becton-Dickinson), and was grown to the stationary phase overnight at $30^{\circ} \mathrm{C}$ in a shaking water bath. Following culture, blastoconidia were collected, washed in PBS, counted by means of a hemocytometer, and adjusted to $10^{6}$ cells $/ \mathrm{ml}$ prior to use.

\section{Assessment of $C$. albicans adhesion and growth on the different restorative materials}

The tests were performed on 24-well plates. Using a sterile technique, each material disk was placed in the bottom of a well and exposed to $10^{6} \mathrm{C}$. albicans in $2 \mathrm{ml}$ of PIM. Following incubation at $37^{\circ} \mathrm{C}$ for $24,48,72$, and $96 \mathrm{~h}$, the test materials were transferred to new wells in a 24-well plate and were washed three times with $2 \mathrm{ml}$ of sterile PBS in order to remove the non-adhering cells. Samples were subsequently used for scanning electron microscopy or for C. albicans growth assessment.

\section{Scanning electron microscopy}

To investigate the ultra-structural $C$. albicans adhesion and growth on the dental materials, each specimen was rinsed in PBS, fixed in $4 \%$ paraformaldehyde in PBS for $15 \mathrm{~min}$, and rinsed four times in distilled water. Dehydration was performed in a series of ethanol solutions of increasing concentrations $(50,70,90$, and twice at $100 \%)$, with a 5 -min dehydration treatment in each solution and a 5-min interval between treatments. The dehydrated specimens were kept overnight in a vacuum oven at room temperature, after which time they were sputter-coated with gold and examined/photographed with a JEOL 6360 LV SEM (Soquelec) operating at a $30 \mathrm{kV}$ accelerating voltage. The experiment was repeated four times and representative photos were taken.

\section{MTT assay}

C. albicans growth on the restorative dental materials was determined using the MTT [(3-(4,5-dimethylthiazol-2-yl)-2,5diphenyltetrazolium-bromide)] test, which is an established spectrophotometric measurement [41]. The MTT reading is proportional to the number of viable cells. The material disks populated with C. albicans were cultured in the presence of $1 \%(\mathrm{v} / \mathrm{v})$ MTT solution $(5 \mathrm{mg} / \mathrm{mL})$ for $4 \mathrm{~h}$, after which time the supernatant was removed and $1 \mathrm{~mL}$ of $\mathrm{HCl}$ in isopropanol $(0.04 \mathrm{~N})$ was added to the well. Fifteen minutes later, $200 \mu \mathrm{L}$ (in triplicate) of solution was transferred from each well to a 96-well flat-bottom plate, and the absorbance of the MTT (formazan) was determined at $550 \mathrm{~nm}$ using an ELISA reader (Model 680, BioRad Laboratories, Mississauga, ON, Canada).

\section{Effect of pre-washes of glass-iomoner cement on C. albicans growth}

Glass-ionomer disks were placed in a 24 -well plate and covered with $3 \mathrm{ml}$ of PBS. This solution was changed each day during 7 days. Washed and non-washed glass-ionomer disks were then seeded with $10^{6}$ C. albicans in $3 \mathrm{ml}$ of PIM medium. Following incubation for $24 \mathrm{~h}$, C. albicans growth was investigated by using a MTT assay, $(\mathrm{n}=4)$.

\section{Effect of exogenous fluoride on C. albicans growth}

C. albicans was grown to the stationary phase $\left(18 \mathrm{~h}\right.$ at $\left.30^{\circ} \mathrm{C}\right)$ in a shaking water bath. The blastoconidia were collected and washed with PBS, and the suspension was adjusted to $10^{6} \mathrm{cells} / \mathrm{ml}$. PIM containing C. albicans $\left(10^{6}\right.$ cells) was incubated with fluoride (50 and $100 \mathrm{ppm}$ ) for $24 \mathrm{~h}$ at $30^{\circ} \mathrm{C}$ under shaking water conditions. C. albicans cultured without fluoride was used as a negative control. C. albicans cultured without fluoride but in the presence of $0.5 \mu \mathrm{g} / \mathrm{ml}$ of amphotericin-B (Sigma-Aldrich, Oakville, ON, Canada) was used as a positive control. Fluoride concentrations were chosen based on previous studies $[42,43]$. Following an incubation period, an MTT assay was performed to determine $C$. albicans growth. The results are presented as the means $\pm \mathrm{SD},(\mathrm{n}=4)$. Following $C$. albicans incubation with fluoride, the cell morphology was analyzed by scanning electron microscopy.

\section{Effect of fluoride on C. albicans morphological changes}

To determine the effect of fluoride on the yeast-to-hyphae transition, C. albicans ( $10^{4}$ cells) was grown in $3 \mathrm{ml}$ PIM containing $10 \%$ FCS. Fluoride was added at different concentrations (50 and $100 \mathrm{ppm})$. Control C. albicans cultures with and without FCS were also performed. The cultures were incubated at $37^{\circ} \mathrm{C}$ for 3 and $6 \mathrm{~h}$ then photographed. Photos were used to record the yeast-to-hyphae transition and to quantify hyphal size. This was measured using an NIH image analyzing program (Image-J Software). The results are the means $\pm \mathrm{SD},(\mathrm{n}=6)$.

\section{Statistical analysis}

Experimental values are expressed as means \pm SD. The statistical significance was determined by means of a one-way ANOVA. Posteriori comparisons were done using Tukey's method. Normality and variance assumptions were verified using the Shapiro-Wilk test and the Brown and Forsythe test, respectively. All of the assumptions were fulfilled. $P$ values were declared significant at $\leq 0.05$. Data were analyzed using the SAS version 8.2 statistical package (SAS Institute Inc., Cary, NC, USA).

\section{Results}

Candida adhesion and growth were dependent on the restorative dental material used

Figure 1 presents the results of the C. albicans adherence and growth on the restorative dental materials. C. albicans adherence after $24 \mathrm{~h}$ of culture was more visible on both the resin acrylic-Dimond D and the Ivocap compared to the composite and glass-ionomer cement materials. In addition, the higher level of $C$. albicans adhesion was obtained with low polishing grit. Indeed, more individual C. albicans and aggregates were observed on the surface of the materials polished with \#800 grit then on those polished with \#4000 grit. Growth measurement by means of MTT assay confirmed the SEM analyses (Figure 2) showing a high number of viable C. albicans on the surface of the Dimond D and Ivocap resin acrylic materials and a low level on the composite and glass-ionomer materials. This specific growth on the material was maintained at 48,72 , and $96 \mathrm{~h}$. A high growth rate was maintained with the acrylic resin at each of these culture periods compared to the composite and glass-ionomer samples (Figure1 and Table 1). The reduced adhesion and growth levels on the glass-ionomer, despite its porous shape, may have been the result of the fluoride enrichment. To validate this hypothesis, glass-ionomer disks were washed during 7 days, with medium changing every 24 h. C. albicans was subsequently 
Citation: Tazi N, Chmielewski W, Semlali A, Lamkhioued B, Akkouch A, et al. (2012) Evaluation of C. albicans Adhesion and Growth on Restorative Dental Materials Enriched or not with Fluoride. J Microbial Biochem Technol 4: 015-021. doi:10.4172/1948-5948.1000066

cultured on the washed and non-washed glass-ionomer cements. As shown in Figure 3, a significantly higher level of C. albicans adhered to and grew on the washed materials, in contrast to the non-washed materials. This indirectly confirms the possible effect of fluoride on reducing C. albicans adhesion and growth.

\section{Fluoride affects C. albicans growth}

Exposure to fluoride reduced C. albicans growth (Figure 4). After $24 \mathrm{~h}$, the fluoride had significantly, and in a dose-dependent manner, reduced C. albicans growth. Indeed, optical density, which is related to viable cell number, dropped from 0.45 in the non-treated Candida culture to 0.3 with $50 \mathrm{ppm}$ of fluoride and to 0.2 with $100 \mathrm{ppm}$ of fluoride. After $48 \mathrm{~h}$, the inhibitory effect of fluoride on C. albicans growth was even greater than at $24 \mathrm{~h}$, despite no significant differences between fluoride concentrations (50 and $100 \mathrm{ppm}$ ) on C. albicans

\begin{tabular}{|l|c|c|c|c|}
\hline \multirow{2}{*}{ Grit \#1200 } & \multicolumn{4}{|c|}{ Absorbance at $\mathbf{5 5 0} \mathbf{~ n m}$} \\
\cline { 2 - 5 } & $\mathbf{2 4} \mathbf{h}$ & $\mathbf{4 8} \mathbf{h}$ & $\mathbf{7 2} \mathbf{~ h}$ & $\mathbf{9 6} \mathbf{~ h}$ \\
\hline Composite & $0.33 \pm 0.04$ & $0.23 \pm 0.001$ & $0.25 \pm 0.02$ & $0.4 \pm 0.03$ \\
\hline Glass-lonomer & $0.26 \pm 0.02$ & $0.24 \pm 0.01$ & $0.21 \pm 0.02$ & $0.2 \pm 0.02$ \\
\hline Diamond D & $0.6 \pm 0.1$ & $0.83 \pm 0.11$ & $0.7 \pm 0.05$ & $0.9 \pm 0.08$ \\
\hline Ivocap & $0.48 \pm 0.08$ & $0.55 \pm 0.09$ & $0.64 \pm 0.06$ & $0.76 \pm 0.14$ \\
\hline Grit \#4000 & \multicolumn{4}{|c|}{ Absorbance at $\mathbf{5 5 0} \mathbf{~ n m}$} \\
\hline & $\mathbf{2 4 h}$ & $\mathbf{4 8} \mathbf{h}$ & $\mathbf{7 2} \mathbf{~}$ & $\mathbf{9 6} \mathbf{h}$ \\
\hline Composite & $0.24 \pm 0.04$ & $0.25 \pm 0.01$ & $0.26 \pm 0.02$ & $0.39 \pm 0.03$ \\
\hline Glass-lonomer & $0.20 \pm 0.02$ & $0.26 \pm 0.01$ & $0.19 \pm 0.02$ & $0.28 \pm 0.02$ \\
\hline Diamond D & $0.64 \pm 0.1$ & $0.79 \pm 0.11$ & $0.48 \pm 0.1$ & $0.66 \pm 0.1$ \\
\hline Ivocap & $0.53 \pm 0.08$ & $0.72 \pm 0.09$ & $0.56 \pm 0.05$ & $0.78 \pm 0.10$ \\
\hline
\end{tabular}

Table 1: C. albicans adhesion and growth onto the surface of different dental restoration materials with different polishing surfaces.

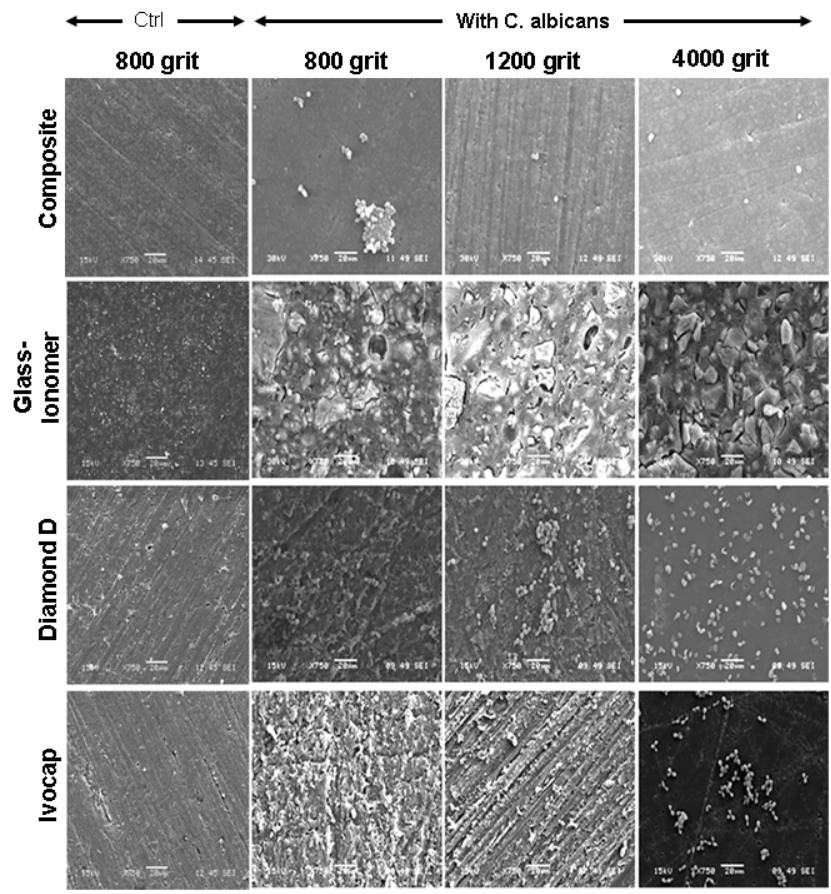

Figure 1: Scanning electron micrographs of $C$. albicans on the surface of various restorative dental materials. $C$. albicans was seeded onto the materials for $24 \mathrm{~h}$ then examined by SEM. Photos are representative of one out of four repetitive experiments.
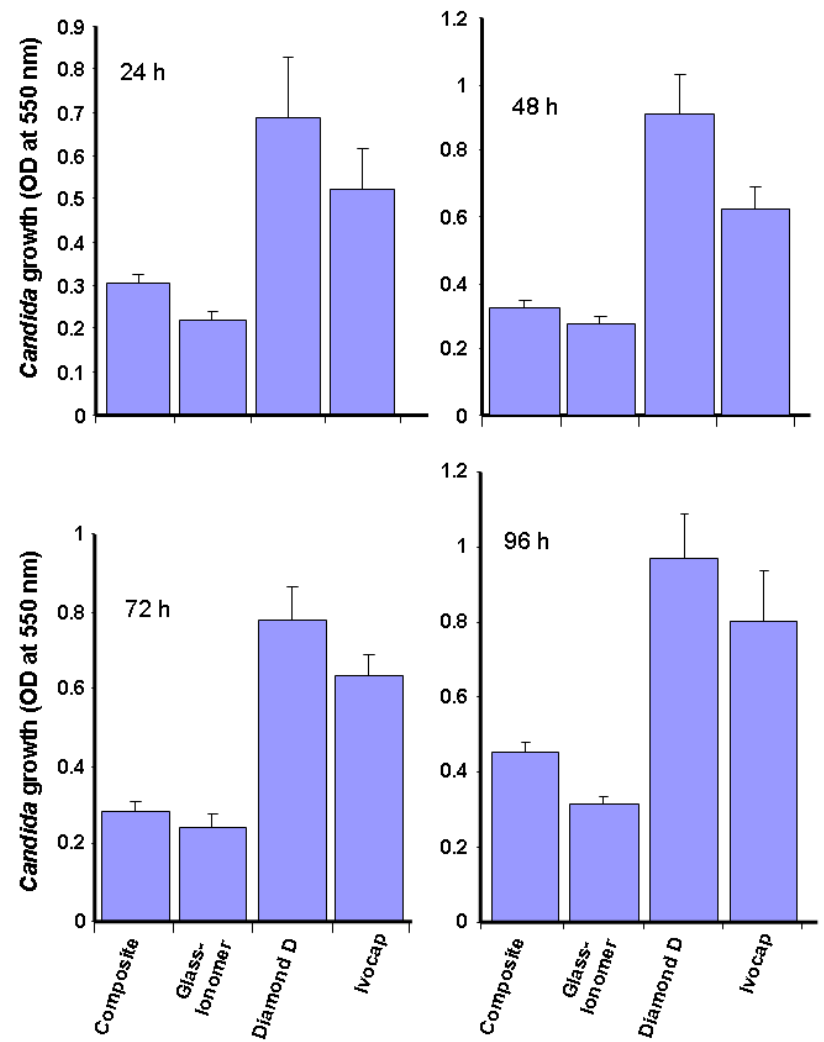

Figure 2: C. albicans growth following culture onto various restorative dental materials. Dental material specimens were polished using \#800 grit, washed extensively with sterile PBS, then seeded with $C$. albicans. The cultures were maintained for $24,48,72$, and $96 \mathrm{~h}$ at $37^{\circ} \mathrm{C}$. Following each culture period, an MTT test was performed on each sample.

growth after $48 \mathrm{~h}$ of treatment. Overall data demonstrates the efficacy of fluoride against $C$. albicans growth.

\section{Fluoride affects C. albicans ultrastructure}

Ultrastructural examination of C. albicans showed typical yeast cells displaying the characteristic bud scars (Figure 5) No development of pseudohyphae (chains of elongated non-separated blastospores) was observed in the cultures with or without fluoride or amphotericin B. Following the addition of fluoride, the external morphology of the cells did not appear as smooth as that of the untreated cells, which indicates a possible loss of cytosolic volume. Indeed, fluoride basically distorted the cell wall surface at high concentrations (Figure $5 \mathrm{~d}$ ). It should be noted that the membrane shape of $C$. albicans cultured in the presence of fluoride (Figures. $5 \mathrm{c}$ and $5 \mathrm{~d}$ ) resembled that observed in the presence of amphotericin B (Figure 5b), which suggests that fluoride and amphotericin B had a comparable effect on the C. albicans membrane. Further studies are needed to confirm this observation.

\section{Fluoride affects $C$. albicans yeast-hyphal transition}

As fluoride affected C. albicans growth, we investigated its possible effect on the yeast to hyphae transition. As shown in Figures 6A and $6 \mathrm{~B}$, fluoride significantly reduced the number of hyphae compared to the control (non-treated Candida cultures). The effect of fluoride was observed at 3 and $6 \mathrm{~h}$ post-treatment, with a greater effect recorded at $6 \mathrm{~h}$ (Figure 6) Fluoride also affected the size of the hyphae. As reported in Figure 6, hyphal size increased with culture time in the C. albicans 
culture not treated with fluoride. In the presence of fluoride at 50 and 100 ppm, however, hyphae size decreased dramatically. The effect was observed at 3 and $6 \mathrm{~h}$ post-treatment. Overall data shows that fluoride affected both the number of yeast-to-hyphae form and the size of the hyphae.

\section{Discussion}

Restorative dental materials are commonly used for teeth restoration. In the oral cavity, these restorative dental materials are in contact with multiple microorganisms, including C. albicans, which may take advantage of the presence of these dental materials to adhere, proliferate, and may cause oral candidiasis. Adhesion and growth of C. albicans may be related to the physico-chemical properties of the material [44-46]. In this study, we analyzed the difference of adhesion and growth of C. albicans on four different restorative dental materials. These materials were subjected to the same polishing protocol prior

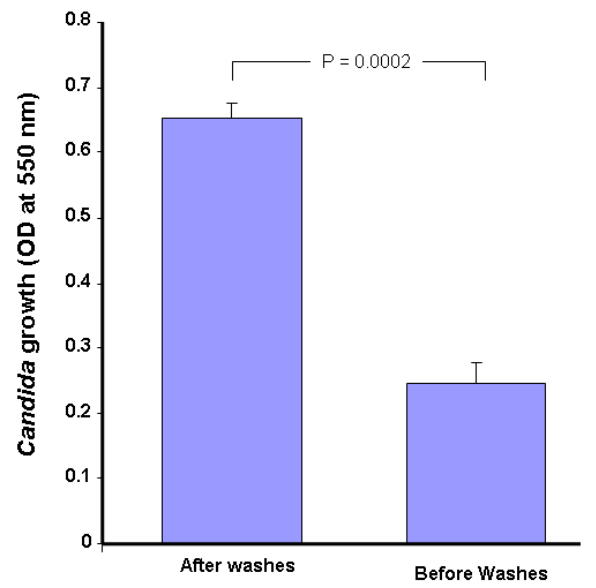

Figure 3: Glass-ionomer controls C. albicans growth through antimicrobial product release. Glass-ionomer samples were washed with sterile PBS during 7 days with a change each day. Washed and non-washed glass-ionomer samples were seeded with C. albicans and cultured for $24 \mathrm{~h}$, after which time C. albicans growth was investigated by means of an MTT test.

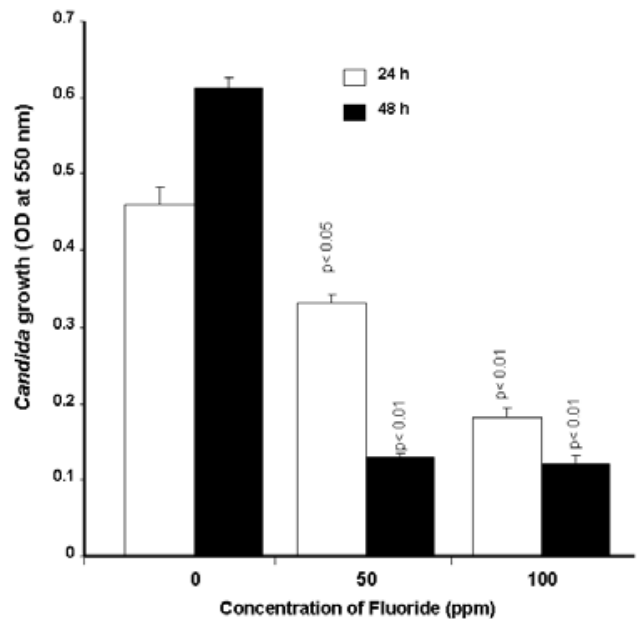

Figure 4: Fluoride reduced C. albicans growth. Yeast was cultured in the presence or absence of fluoride (50 and $100 \mathrm{ppm}$ ) for 24 and $48 \mathrm{~h}$. C. albicans growth was then evaluated by means of an MTT test.

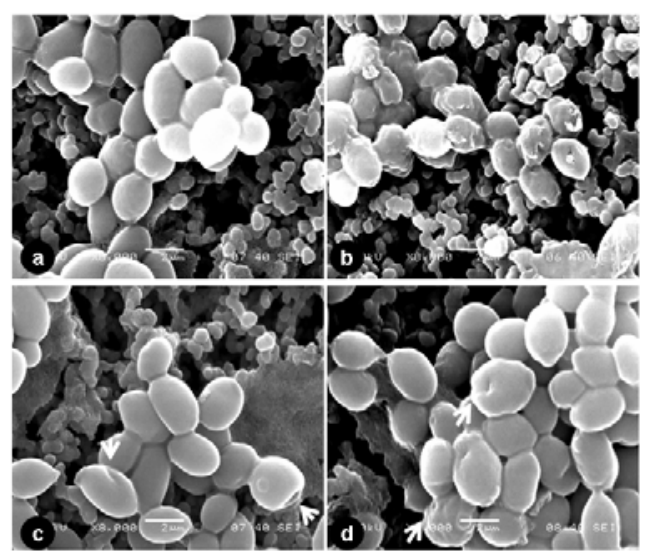

Figure 5: Scanning electron microscopy analyses. C. albicans was cultured in the presence (c and d) of fluoride at 50 and $100 \mathrm{ppm}$, respectively. (b) C. albicans $\mathrm{g} / \mathrm{ml}$ of amphotericin B only. (a)?culture in the presence of $5 \mathrm{C}$. albicans culture without fluoride and without amphotericin B. C. albicans wal integrity was observed by scanning electron microscopy. The arrows indicate cell wall modifications.
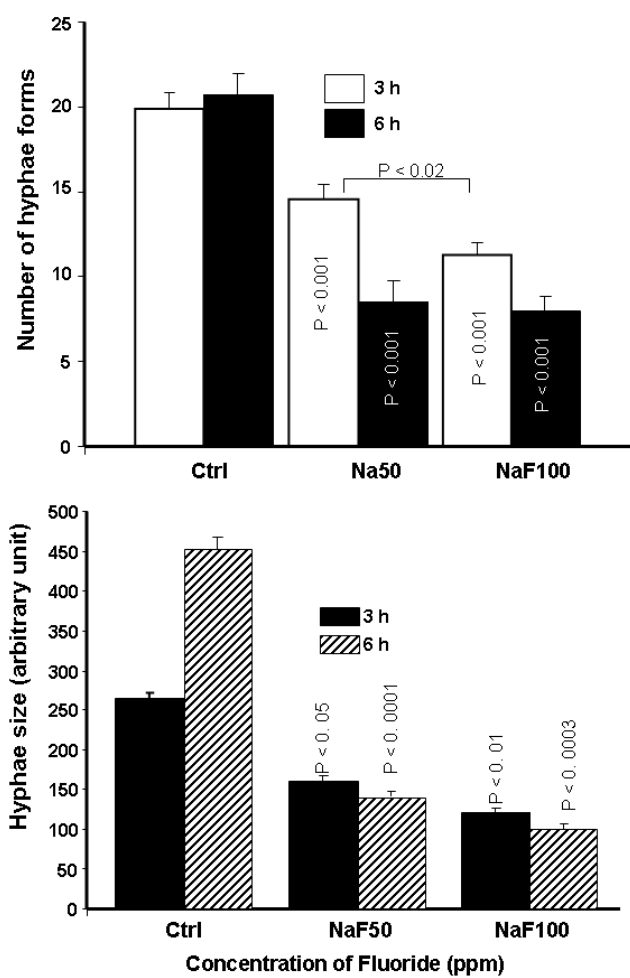

Figure 7: Fluoride modulated the number and the size of $C$. albicans hyphal forms. Following culture in the presence or absence of fluoride, the number and the size of the hyphal forms were investigated at 3 and $6 \mathrm{~h}$.

to use. Data shows that the C. albicans adhered well and proliferated when in contact with the Diamond D and Ivocap resin acrylic surfaces. These observations are in accordance with those previously reported with different acrylic resins $[47,48]$. The high adherence of C. albicans to acrylic resin may be due to the surface physico-chemical properties. Indeed, it has been reported that the adhesion of various microorganisms, including C. tropicalis, C. glabrata, C. dubliniensis, and $C$. albicans could be promoted by the surface free energy values, 
as hydrophobic microorganisms appear to adhere more to acrylic surfaces [49]. With an acrylic resin preparation protocol, it is possible to modulate material surface wettability through acid-base interactions [50]. Through this wettability, the adhesion of microorganisms such as C. albicans may be promoted [51], which supports the data presented in our study. Further investigations are required to elucidate the mechanisms involved in C. albicans adhesion to acrylic resin but not to other dental materials such as composite resin. This study demonstrated a low level of $C$. albicans adhesion and growth using the Filtek TM Supreme Ultra syringe. These data are in accordance with those reported with comparable material and with $S$. mutans adhesion and growth [52]. The reduced C. albicans adhesion to the composite material tested in our study may be due to the surface roughness, including the absence of pores. It is well documented that the surface roughness of intraoral hard surfaces has a major impact on bacterial adhesion and retention. Rougher surfaces such as crowns, implant abutments, and denture bases retain more plaque than do smoother ones $[53,54]$. In patients with inadequate oral hygiene, the surface roughness of provisional restorations is sometimes associated with the onset of subclinical and clinical inflammation [55,56], while smooth intraoral structures ensure patient comfort and facilitate oral hygiene [57]. This may not, however, apply to all restorative material.

In the present study, we demonstrate low adhesion and proliferation levels of $C$. albicans when cultured onto a rough, porous glass-ionomer material. Our hypothesis is that even under favorable physical conditions (non-smooth, porous material); the reduced level of C. albicans adhesion and growth is due to the chemical composition of the glass-ionomer used. As previously reported, glass-ionomer contains fluoride, a chemical component. Fluoride present in the dental material may act as antimicrobial agent. In vitro studies have shown that amalgam and glass-ionomer may possibly inhibit the growth of cariogenic bacteria and the cariogenicity of oral biofilms [58,59]. An in vivo study using 20 volunteers showed that glass-ionomer material provided protection against secondary caries [60].

To confirm the role of fluoride on C. albicans growth inhibition on glass-iomoner, we activated fluoride release from this material during 7 days, after which time we investigated C. albicans adhesion/growth. Our data revealed both high adhesion and growth on the fluoridedepleted glass-ionomer materials compared to the non-depleted ones. This confirms that the inhibition of $C$. albicans adhesion and growth on glass-ionomer may be due to the presence of fluoride. To support this hypothesis, we tested the efficacy of exogenous fluoride against C. albicans pathogenesis. Our results show that fluoride reduced C. albicans growth and the yeast-to-hyphae morphological transition. In C. albicans, hyphal formation is known to promote virulence by several mechanisms including invasion of epithelial cell layers [61], breaching and damaging endothelial cells [62], and following phagocytosis, $C$. albicans hyphal growth can promote lysis of macrophages and neutrophils [63].

Although several groups have investigated the efficacy of exogenous fluoride against bacterial growth and biofilm formation $[64,65]$, this study is the first to investigate the direct effect of fluoride on C. albicans pathogenesis. It therefore suggests the possible integration of fluoride in all restorative dental materials as an antimicrobial agent to prevent microorganism adhesion, growth, and biofilm formation. Further studies will be required to determine the integration techniques, long-term efficient concentrations, and the molecular mechanisms involved in the antimicrobial effect of fluoride. In conclusion, using various restorative dental materials, this study shows that $C$. albicans adhesion and growth is specific to each of these materials, as even with facilitating physical properties, the glass-ionomer surface showed low yeast adhesion and growth levels. This may be due to the presence of fluoride, as this exogenous component was able to control C. albicans growth and morphological transition.

\section{Acknowledgements}

This study was supported by grants from the Natural Sciences and Engineering Research Council of Canada (NSERC) Discovery Program (MR) and the NIH/R01DE017486-01A1 (MAG and MR)

\section{References}

1. Hannig C, Hannig M (2009) The oral cavity a key system to understand substratum-dependent bioadhesion on solid surfaces in man. Clin Oral Investig 13: $123-139$

2. Smith AJ, Lumley PJ, Tomson PL, Cooper PR (2008) Dental regeneration and materials: a partnership. Clin Oral Investig 12: 103-108.

3. Marsh PD (2010) Microbiology of dental plaque biofilms and their role in ora health and Caries. Dent Clin North Am 54: 441-454.

4. Williams DW, Kuriyama T, Silva S, Malic S, Lewis MA (2011) Candida biofilms and oral candidosis: treatment and prevention. Periodontol 2000 55: 250-265.

5. Peutzfeldt A, García-Godoy F, Asmussen E (1997) Surface hardness and wear of glass ionomers and compomers. Am J Dent 10: 15-17.

6. Forsten $L$ (1998) Fluoride release and uptake by glass-ionomers and related materials and its clinical effect. Biomaterials 19: 503-508.

7. Hibino Y, Kuramochi K, Hoshino T, Moriyama A, Watanabe Y, et al. (2002) Relationship between the strength of glass ionomers and their adhesive strength to metals. Dent Mater 18: 552-557.

8. Mitsuhashi A, Hanaoka K, Teranaka T (2003) Fracture toughness of resinmodified glass ionomer restorative materials: effect of powder/liquid ratio and powder particle size reduction on fracture toughness. Dent Mater 19: 747-757

9. Ikeda T, Sidhu SK, Omata Y, Fujita M, Sano H (2005) Colour and translucency of opaque-shades and body-shades of resin composites. Eur J Oral Sci 113 170-173.

10. Schmeling M, Meyer-Filho A, de Andrada MA, Baratieri LN (2010) Chromatic influence of value resin composites. Oper Dent 35: 44-49.

11. Teughels W, Van Assche N, Sliepen I, Quirynen M (2006) Effect of materia characteristics and/or surface topography on biofilm development. Clin Oral Implants Res 17: 68-81.

12. Lindsay D, von Holy A (2006) Bacterial biofilms within the clinical setting: what healthcare professionals should know. J Hosp Infect 64: 313-325.

13. Jain A, Gupta Y, Agrawal R, Khare P, Jain SK (2007) Biofilms--a microbial life perspective: a critical review. Crit Rev Ther Drug Carrier SysT 24: 393-443.

14. Ramage G, Mowat E, Jones B, Williams C, Lopez-Ribot J (2009) Our current understanding of fungal biofilms. Crit Rev Microbiol 35: 340-355.

15. Daneshmehr L, Matin K, Nikaido T, Tagami J (2008) Effects of root dentin surface coating with all-in-one adhesive materials on biofilm adherence. J Dent 36: $33-41$.

16. Kolenbrander PE, London J (1993) Adhere today, here tomorrow: oral bacteria adherence. J Bacteriol 175: 3247-3252.

17. Chavant P, Martinie B, Meylheuc T Bellon-Fontaine MN, Hebraud M (2002) Listeria monocytogenes LO28: surface physicochemical properties and ability to form biofilms at different temperatures and growth phases. Appl Environ Microbiol 68: 728-737.

18. Pereni Cl, Zhao Q, Liu Y, Abel E (2006) Surface free energy effect on bacterial retention. Colloids Surf B Biointerfaces 48: 143-147.

19. Rodrigues LR (2011) Inhibition of bacterial adhesion on medical devices. Adv Exp Med Biol 715: 351-367.

20. Endo T, Finger WJ, Kanehira M, Utterodt A, Komatsu M (2010) Surface texture and roughness of polished nanofill and nanohybrid resin composites. Dent Mater J 29: 213-223. 
Citation: Tazi N, Chmielewski W, Semlali A, Lamkhioued B, Akkouch A, et al. (2012) Evaluation of C. albicans Adhesion and Growth on Restorative Dental Materials Enriched or not with Fluoride. J Microbial Biochem Technol 4: 015-021. doi:10.4172/1948-5948.1000066

21. Yazici AR, Muftu A, Kugel G (2007) Three-dimensional surface profile analysis of different types of flowable restorative resins following different finishing protocols. J Contemp Dent Pract 8: 9-17.

22. Fucio SBP, Carvalho FG, Sobrinho LC, Sinhoreti MAC, Puppin-Rontani RM (2008) The influence of 30-day-old Streptococcus mutans biofilm on the surface of esthetic restorative materials-an in vitro study. J Dent 36: 833-839.

23. Kantorski KZ, Scotti R, Valandro LF, Bottino MA, Koga-Ito CY, et al. (2009) Surface roughness and bacterial adherence to resin composites and ceramics. Oral Health Prev Dent 7: 29-32.

24. Li L, Finnegan MB, Ozkan S, Kim Y, Lillehoj PB, et al. (2010) In vitro study of biofilm formation and effectiveness of antimicrobial treatment on various dental material surfaces. Mol Oral Microbiol 25: 384-390.

25. Pereira-Cenci T, Cenci MS, Fedorowicz Z, Marchesan MA (2009) Antibacterial agents in composite restorations for the prevention of dental caries. Cochrane Database Syst Rev : CD007819.

26. Neelakantan P, John S, Anand S, Sureshbabu N, Subbarao C (2011) Fluoride release from a new glass-ionomer cement. Oper Dent 36: 80-85.

27. Poggio C, Arciola CR, Rosti F, Scribante A, Saino E, et al. (2009) Adhesion of Streptococcus mutans to different restorative materials. Int J Artif Organs 32: $671-677$

28. Featherstone JD (1996) Modeling the caries-inhibitory effects of dental materials. Dent Mater 12: 194-197.

29. Naorungroj S, Wei HH, Arnold RR, Swift EJ Jr, Walter R (2010) Antibacterial surface properties of fluoride-containing resin-based sealants. J Dent 38: $387-$ 391.

30. Nakajo K, Imazato S, Takahashi Y, Kiba W, Ebisu S, et al. (2009) Fluoride released from glass-ionomer cement is responsible to inhibit the acid production of caries-related oral streptococci. Dent Mater 25: 703-708.

31. Akpan A, Morgan R (2002) Oral candidiasis. Postgrad Med J 78: 455-459.

32. Cannon RD, Holmes AR, Mason AB, Monk BC (1995) Oral Candida: clearance, colonization, or candidiasis? J Dent Res 74: 1152-1161.

33. Sanita PV, Pavarina AC, Giampaolo ET, Silva MM, Mima EG, et al. (2011) Candida spp prevalence in well controlled type 2 diabetic patients with denture stomatitis. Oral Surg Oral Med Oral Pathol Oral Radiol Endod 111: 726-733.

34. Gendreau L, Loewy ZG (2011) Epidemiology and Etiology of Denture Stomatitis. J Prosthodont 20: 251-260.

35. Nett JE, Marchillo K, Spiegel CA, Andes DR (2010) Development and validation of an in vivo Candida albicans biofilm denture model. Infect Immun 78: 36503659.

36. D'Enfert C (2006) Biofilms and their role in the resistance of pathogenic Candida to antifungal agents. Curr Drug Targets 7: 465-470.

37. Kuhn DM, Ghannoum MA (2004) Candida biofilms: antifungal resistance and emerging therapeutic options. Curr Opin Investig Drugs 5: 186-197.

38. Yoshinari M, Kato T, Matsuzaka K, Hayakawa T, Inoue T, et al.( 2006) Adsorption behavior of antimicrobial peptide histatin 5 on PMMA. J Biomed Mater Res B Appl Biomater 77: 47-54.

39. Alves PV, Lima Filho RM, Telles E, Bolognese A (2007) Surface roughness of acrylic resins after different curing and polishing techniques. Angle Orthod 77: 528-531.

40. Gillum AM, Tsay EY, Kirsch DR (1984) Isolation of the Candida albicans gene for orotidine-5-phosphate decarboxylase by complementation of S.cerevisiae ura3 and E.coli pyrF mutations. Mol Gen Genet 198: 179-182.

41. Akerey B, Le-Lay C, Fliss I, Subirade M, Rouabhia M (2009) In vitro efficacy of nisin Z against Candida albicans adhesion and transition following contact with normal human gingival cells. J Appl Microbiol 107: 1298-1307.

42. Flisfisch S, Meyer J, Meurman JH, Waltimo T (2008) Effects of fluorides on Candida albicans. Oral Dis 14: 296-301.

43. Kamotsay K, Herczegh A, Rozgonyi F, Nász I, Gintner Z, et al. (2002) Effect of fluoride on cariogenic oral microorganisms: an in vitro study. Acta Microbiol Immunol Hung 49: 47-58

44. Chin MY, Sandham A, Pratten J, De Vries J, Van der Mei HC, et al. (2006) Multivariate analysis of surface physico-chemical properties controlling biofilm formation on orthodontic adhesives prior to and after fluoride and chlorhexidine treatment. J Biomed Mater Res B Appl Biomater 78: 401-408.

45. Dong C, Zhang FQ (2009) Effect of denture base materials on mRNA expression of the adhesion-associated genes from the Streptococcus mutans biofilms. J Oral Rehabil 36: 894-901.

46. Mabboux F, Ponsonnet L, Morrier JJ, Jaffrezic N, Barsotti O (2004) Surface free energy and bacterial retention to saliva-coated dental implant materials-an in vitro study. Colloids Surf B Biointerfaces 39: 199-205.

47. Straioto FG, Alves R, Filho AP, Del Bel Cury AA (2010) Polytetrafluoroethylene added to acrylic resin: surface properties and Candida albicans adherence. Am J Dent 23: 201-204.

48. Young B, Jose A, Cameron D, McCord F, Murray C, et al. (2009) Attachment of Candida albicans to denture base acrylic resin processed by three different methods. Int J Prosthodont 22: 488-489.

49. Moura JS, da Silva WJ, Pereira T, Del Bel Cury AA, Rodrigues Garcia RC (2006) Influence of acrylic resin polymerization methods and saliva on the adherence of four Candida species. J Prosthet Dent 96: 205-211.

50. Sipahi C, Anil N, Bayramli E (2001) The effect of acquired salivary pellicle on the surface free energy and wettability of different denture base materials. $J$ Dent 29: 197-204.

51. Yildirim MS, Hasanreisoglu U, Hasirci N, Sultan N (2005) Adherence of Candida albicans to glow-discharge modified acrylic denture base polymers J Oral Rehabil 32: 518-525.

52. Montanaro L, Campoccia D, Rizzi S, Donati ME, Breschi L, et al. (2004) Evaluation of bacterial adhesion of Streptococcus mutans on denta restorative materials. Biomaterials 25: 4457-4463.

53. Borchers L, Tavassol F, Tschernitschek H (1999) Surface quality achieved by polishing and by varnishing of temporary crown and fixed partial denture resins. J Prosthet Dent 82: 550-556.

54. Quirynen M, Bollen CM (1995) The influence of surface roughness and surface-free energy on supra- and subgingival plaque formation in man. J Clin Periodontol 22: 1-14

55. Van Dijken JW, Sjostrom S, Wing K (1987) Development of gingivitis around different types of composite resin. J Clin Periodontol 14: 257-260.

56. Janus J, Fauxpoint G, Arntz Y, Pelletier H, Etienne O (2010) Surface roughness and morphology of three nanocomposites after two different polishing treatments by a multitechnique approach. Dent Mater 26: 416-425.

57. Jefferies SR (2007) Abrasive finishing and polishing in restorative dentistry: a state-of-the-art review. Dent Clin North Am 51: 379-397.

58. Moura JS, Lima EM, Paes Leme AF, Del Bel Cury AA, Tabchoury CP, et al. (2004) Effect of luting cement on dental biofilm composition and secondary caries around metallic restorations in situ. Oper Dent 29: 509-514.

59. Osorio E, Osorio R, Toledano M, Quevedo-Sarmiento J, Ruiz-Bravo A (2010) Influence of different resin-based restorative materials on mutans streptococci adhesion. An in vitro study Am J Dent 23: 275-278.

60. Sousa RP, Zanin IC, Lima JP, Vasconcelos SM, Melo MA, et al. (2009) In situ effects of restorative materials on dental biofilm and enamel demineralisation. J Dent 37: 44-51.

61. Kumamoto CA, Vinces MD (2005) Contributions of hyphae and hypha-coregulated genes to Candida albicans virulence. Cell Microbiol 7: 1546-1554.

62. Jong AY, Stins MF, Huang SH, Chen SH, Kim KS (2001) Traversal of Candida albicans across human blood-brain barrier in vitro. Infect Immun 69: 45364544

63. Korting HC, Hube B, Oberbauer S, Januschke E, Hamm G, et al. (2003) Reduced expression of the hyphal-independent Candida albicans proteinase genes SAP1 and SAP3 in the efg1 mutant is associated with attenuated virulence during infection of oral epithelium. J Med Microbiol 52: 623-632.

64. Knight GM, McIntyre JM, Craig GG, Mulyani, Gully NJ (2005) An in vitro mode to measure the effect of a silver fluoride and potassium iodide treatment on the permeability of demineralized dentine to Streptococcus mutans. Aust Dent $\mathrm{J}$ 50: 242-245.

65. Van der Mei HC, Engels E, de Vries J, Busscher H J (2008) Effects of amine fluoride on biofilm growth and salivary pellicles. Caries Res 42: 19-27. 